\title{
Uso Del Misoprostol Intrarectal en el Tratamiento de la Atonia Uterina
}

\author{
Iván E. Gómez MD,*; Walter E. Pinzón MD.**; Ricardo Rueda S. MD,***; Andrés Sarmiento MD,****
}

\section{RESUMEN}

El misoprostol como potente uterotonico ha sido propuesto en el manejo de la hemorragia postparto secundaria a atonia uterina. Se refieren dos casos de pacientes con èsta complicacion que se beneficiaron de su uso. Se comentan aspectos de su dosificaciòn y utilidad en el manejo del tercer periodo del parto.

PALABRAS CLAVES: Misoprostol, atonia uterina, intrarectal.

\section{ABSTRACT}

The use of Misoprostol as an uterotonic agent has been referred in the management of postpartum hemorrage secondary to uterine atony. We present two cases of patients who benefit from the use of this medicaction. Comments upon the use of Misoprostol in the management of the third period of delivery are made.

KEY WORDS: Misoprostol, uterine atony, intrarectal.

La hemorragia postparto es la principal causa de mortalidad materna a nivel mundial con aproximadamente 100.000 a 150.000 muertes anuales en el postparto inmediato, esto sin tener en cuenta la morbilidad en pacientes que responden parcialmente a los esquemas terapéuticos.

La mayoría de protocolos descritos para el manejo de la hemorragia post-parto coinciden en un manejo medicoquirurgico escalonado y secuencial. Contemplan en primera instancia evaluar una posible retención de los productos de la concepción al igual que identificar lesiones del canal del parto. Una vez descartados estos dos eventos, se intuye atonía uterina y se procede a manejar de manera activa con medicamentos de actividad oxitócica reconocida. Para tal fin se dispone usualmente de oxitocina y ergometrina administradas por vía intravenosa o intramuscular. Si a pesar del manejo instaurado persiste el sangrado, existe la posibilidad teórica de utilizar prostaglandinas endovenosas o intramiometriales. Una vez cumplidos estos pasos, si el sangrado continúa se debe proponer un manejo quirúrgico que podría contemplar desde la embolización o ligadura de la arteria ilíaca interna, hasta la sutura hemostatica

* Residente II, Universidad El Bosque, Hospital Simón Bolívar, Bogotà.

** Residente IV, Universidad El Bosque, Hospital Simón Bolívar.

*** Médico Ginecobstetra, Fundación Santafé de Bogota. Director Cientìfico REPROTEC, Asociación Médica de los Andes, Bogotà.

**** Médico Ginecobstetra, Coordinador Académico Unidad de Medicina Materno-Fetal, Hospital Simón Bolívar. del útero (B-lynch); y como último recurso, la histerectomía.

Existen en la literatura médica, referencias sobre el uso de diferentes prostaglandinas como tratamiento coadyuvante para la atonía uterina. Dentro de estas referencias, las más recientes plantean el uso de misoprostol, un análogo de la prostaglandina E 1, por vía transrrectal para el control de la hemorragia uterina postparto secundaria a atonía uterina. Aparentemente el misoprostol es un fármaco mucho mas potente que otros uterotonicos y las experiencias iniciales con su uso han reportado resultados muy favorables.

Alentados por las referencias bibliográficas que han reportado al misoprostol como una excelente alternativa terapéutica en el manejo de la atonía uterina, en el Hospital Simón Bolívar y en la Fundación Santafè de Bogotá se ha utilizado el fármaco en forma anecdótica como una medida desesperada en casos de atonía uterina de difícil control. A continuación se describen dos casos muy explícitos en donde los autores han utilizado el misoprostol en el tratamiento de la atonía uterina postparto con resultados muy satisfactorios y que obviaron otros procedimientos mayores.

\section{Caso 1}

Paciente de 31 años G1 P1 C1 en postoperatorio inmediato de cesárea segmentaria transperitoneal indicada por detención secundaria de la fase activa por desproporción cefalopelvica. En recuperación desarrolla hemorragia vaginal profusa. Valorada por el ginecobstetra se evidencia 
útero hipotonico supraumbilical que no ha respondido al masaje ni a la administración continua de oxitocina endovenosa. Con diagnostico de atonía uterina se inicia manejo en los siguientes minutos con infusión de cristaloides y se insiste con carga endovenosa de 10 unidades de oxitocina y con la aplicación simultanea de maleato de metilergonovina, sin obtener respuesta adecuada. La paciente evoluciona desfavorablemente con hipotensión progresiva y compromiso de su gasto urinario, a pesar de la infusión de cristaloides y de glóbulos rojos empaquetados. En consideración a la paridad de la paciente y a la alta posibilidad que requerirá un manejo quirúrgico, se decide como ultimo recurso la aplicación de misoprostol.

Se administran cinco (5) tabletas de $200 \mathrm{mg}$ del fármaco por vía transrrectal. Inmediatamente bajo anestesia general se realiza revisión manual de cavidad uterina descartando la presencia de restos placentarios; se colocan compresas dentro de la cavidad endometrial logrando una adecuada respuesta uterotónica. Se terminan de transfundir cuatro unidades de glóbulos rojos empaquetados con posterior recuperación de las cifras tensionales y del gasto urinario. Seis horas mas tarde se da salida a la habitación.

\section{Caso 2}

Paciente de 35 años, grávida 4, partos 4, quien es remitida de un centro de primer nivel por presentar sangrado profuso postparto vaginal eutocico, secundario a atonía uterina. La paciente ingresa en malas condiciones generales, hemodinámicamente inestable, con sangrado transvaginal profuso. Bajo anestesia general se realiza revisión manual de cavidad uterina y del canal del parto y confirmando presencia de útero atónico. Se procede a la aplicación inmediata de cinco (5) tabletas de misoprostol de $200 \mathrm{mg}$ intrarrectales con lo que se obtiene, en un lapso de cinco minutos, disminución progresiva del sangrado y contracción tónica sostenida del útero. Se procede a transfundir cuatro unidades de glóbulos rojos empaquetados y evaluación de la función renal por oliguria en las dos primeras horas postprocedimiento. La paciente evoluciona favorablemente siendo dada de alta de la institución a las 48 horas.

\section{Comentarios}

Existen múltiples referencias en la literatura obstétrica que confirman la actividad oxitócica del misoprostol al actuar estimulando el útero gestante por unión selectiva a receptores de prostaglandina E2 subtipos EP-2 y EP-3, siendo posible su utilización en inducción del trabajo de parto con resultados altamente favorables. Partiendo de ésta evidencia y con la muy satisfactoria experiencia que hemos tenido con la utilización del misoprostol como inductor del trabajo de parto, se propuso el uso de éste medicamento en el manejo de la tercera fase del trabajo de parto, específicamente en casos de atonía uterina.

Dentro de los beneficios teóricos referidos se encuentran su alta efectividad y potencia como uterotonico, una baja tasa de efectos secundarios y el no estar contraindicado en pacientes hipertensas de cualquier etiología, esto incluye especialmente preeclámpticas. En cuanto a su administración, se encuentra ideal el uso de la vía transrrectal ya que la absorción del misoprostol es dependiente de mucosas; además es ésta la vía indicada en pacientes hipotensas, en shock hipovolemico, o bajo efectos de anestesia general lo que imposibilitaría su uso por vía oral. Así mismo el sangrado vaginal activo y profuso es una contraindicación para su uso intrauterino o intravaginal pues interferiría con la absorción del fármaco.

A pesar de existir controversias por desconocerse la farmacocinética del misoprostol por vía transrrectal y el tiempo en lograrse concentraciones séricas ideales por administración oral o transvaginal; sobre la base de las referencias bibliográficas y los hallazgos iniciales, podría considerarse $1000 \mathrm{mg}$ intrarrectales como una dosificación adecuada. Consideramos al misoprostol como una alternativa real en el manejo de la atonía uterina que no responda a oxitocina y/o ergometrina, o en el caso fortuito de no disponer de estos medicamentos, condición ésta de relativa frecuencia en nuestras entidades hospitalarias.

El presente artículo debe servir como base para elaborar protocolos que permitan diseñar curvas de farmacocinética y farmacodinamia que deriven en definir la dosificación ideal intrarectal del misoprostol para el manejo de la atonía uterina. Debe además alentar a obstetras a utilizarlo como una excelente alternativa en casos de hemorragia postparto secundaria a atonía uterina que no responde a las medidas convencionales. Las características del fármaco, es decir su alto poder uterotonico, bajo costo, fácil administración, disponibilidad, y sencillo almacenamiento, lo hacen ideal para su manejo en instituciones no solo estatales sino privadas. En nuestra limitada experiencia con el misoprostol en obstetricia, parece ser ésta otra aplicación terapéutica muy razonable para éste fármaco dentro de nuestra especialidad.

Esperamos que otros centros hospitalarios se beneficien de las bondades del fármaco en el manejo de una temida complicación obstétrica como lo es la hemorragia post-parto, fuente habitual de morbi-mortalidad materna y su estrés médico.

\section{REFERENCIAS}

1. Tagaki S, Yoshida $\mathrm{T}$, et al: The effects of intramyometrial injections of prostaglandin F2a on severe postpartum hemorrage. Prostaglandins 1976; 12: 565.

2. Jacobs M, Arias F: Intramyometrial prostaglandin F2a in the treatment of severe postpartum hemorrage. Obstet Gynecol 1980; 55: 665-6.

3. Mc Donald S, Prediville W, Blair E: Randomised controlled trial of oxytocin alone versus oxytocin and ergometrine in active management of third stage of labour. BMJ 1993; 307: 1167-71.
4. Bamigboye A, Hofmeyr J, Merrell D: Rectal misoprostol in the prevention of postpartum hemorrhage: A placebo-controlled trial. Am J Obstet Gynecol 1998; 179:1043-6.

5. O' Brien et al: Rectally administered Misoprostol for the treatment of postpartum hemorrhage unresponsive to oxitocin and ergometrine: A descriptive study. Obstet Gynecol 1998; 92:212-4.

6. El-Refaey H. O' Brien: Misoprostol for third stage of labour. Lancet 1996; 347: 1257. 